\title{
Reference luminal diameters of the carotid arteries among healthy Nigerian adults
}

\author{
S.P.K. Kpuduwei ${ }^{1}{ }^{2,3}{ }^{3}$, E.K. Kiridi ${ }^{4}$, H.B. Fawehinmi' ${ }^{1}$, G.S. Oladipo ${ }^{1}$ \\ ${ }^{1}$ Department of Anatomy, University of Port Harcourt, Port Harcourt, Nigeria \\ ${ }^{2}$ Department of Surgery, Federal Medical Centre, Yenagoa, Nigeria \\ ${ }^{3}$ Division of Neurosurgery, Department of Surgery, National Hospital Abuja, Nigeria \\ ${ }^{4}$ Department of Radiology, Niger Delta University, Wilberforce Island, Bayelsa State, Nigeria \\ [Received: 8 April 2021; Accepted: 4 May 2021; Early publication date: 14 June 2021]
}

Background: The carotid arteries serve as major blood supply to the head and neck region of the body. Understanding their structure and function in the pathogenesis of stroke and in interventional neuroradiology due to luminal stenosis, atherosclerosis and wall stiffness is paramount. Doppler ultrasound scan plays key role in the early diagnosis of the pathologies of the arteries as it is an affordable, accessible, reliable and non-invasive clinical tool. Knowing normal average diameter of the carotid arteries among healthy individuals is important in making correct clinical diagnosis in any population. The aim of the study was to determine mean diameters of the carotid arteries among healthy adult Nigerians for reference.

Materials and methods: This was a prospective study involving 104 healthy Nigerians within the ages of 18 and 65 years who had their carotid arteries scanned on both sides and each diameter was measured. A 95\% confidence level was used; a p-value of $<0.05$ was significant.

Results: Of the studied population, 62 were males and 42 were females, and the average age of the subjects was $28.32 \pm 9.09$ years. From this study, the average luminal diameter of the common carotid artery $=0.61 \pm 0.08 \mathrm{~cm}$, internal carotid artery $=0.60 \pm 0.08 \mathrm{~cm}$ and external carotid artery $=0.49 \pm 0.10 \mathrm{~cm}$. The results showed that although, there are differences in measurements between the two sexes (males slightly higher than females in common carotid artery) and between right and left sides (with right side slightly higher), they are not statistically significant.

Conclusions: This sonographic study on healthy Nigerian adults has given us normal reference values of the luminal diameters of the carotid arteries among Nigerians, which clinicians can make reference to, when assessing carotid artery diameters of patients in Nigeria. (Folia Morphol 2022; 81, 3: 579-583)

Key words: carotid artery, luminal diameter, ultrasound scan, reference values, Nigerians 


\section{INTRODUCTION}

Blood supply to the brain is one of the key reasons why neurosurgeons and neurologists are interested in the structure and function of the carotid arteries, especially the internal carotid artery. The carotid arteries also play cardinal role in regulating the volume and pressure of blood that reaches the head and neck in addition to supplying oxygenated blood, as they are known to be influenced by cardiac outputs and blood pressure. However, the internal carotid artery (ICA) also serves as a gateway for vascular interventions in the brain, in addition to supplying blood to the cerebrum $[8,13,23]$. Stroke is global killer and the relationship between carotid artery diameter and cardiovascular risk for cerebrovascular events with the attendant compensatory dilation in atherosclerosis has been established [10, 20]. Interestingly, the carotid artery is also known to suffer several disease conditions that may affect its major function [14]. Atherosclerosis, luminal stenosis, wall stiffness may all affect its effective diameter, elasticity, and the velocity and volume of blood it can supply to the brain [25].

Ultrasonography is currently the first and preferred mode of assessment of the carotid arteries by clinicians because it is easily affordable, accessible, reliable with little or no complications as a non-invasive method with ease for follow-up [12, 17, 19, 24]. However, it would be difficult to state the exact degree of stenosis or dilation of the carotid arteries without normal reference values in the patient's environment, as there are indications to show racial variations in the size of the arteries [7]. In Nigeria, most clinicians use reference values in foreign texts to deduce their conclusion on the status of the luminal diameters of the carotid arteries, especially when there are no obvious atherosclerotic plagues to suggest pathology. This is partly because there is no existing established data of normal standardized reference values from healthy Nigerian subjects.

The aim of this study was to determine the mean luminal diameters of the carotid arteries in healthy adults to serve as normal reference values for clinical diagnostics among Nigerian patients.

\section{MATERIALS AND METHODS}

One hundred and four (104) healthy Nigerian adults between the ages of 18 and 65 years were sampled in this prospective cross-sectional study. The study was approved by the Ethics Committee of the University of Port Harcourt. Adequate consent from all participants was obtained. Subjects with history and overt signs of cardiovascular, cerebrovascular and metabolic disorders were excluded. Using ultrasound scan machine "EcoMed" version VERTU-3 Portable USG with linear transducer and frequency of $7.0 \mathrm{MHz}$, all participants were scanned by experienced radiologist. Sonographic measurements of luminal diameter for common carotid artery (CCA), ICA and external carotid artery (ECA) on both right and left sides about $1 \mathrm{~cm}$ from the carotid bifurcation in grayscale and B-mode were made. The measurements were done according to the recommendations of the Japan Society of Ultrasonics in Medicine and the American Society of Echocardiography using two-dimensional (2D) ultrasound images in end-diastolic phase. The diameter was basically obtained as the distance between one intimal layer and its opposite intimal layer $[18,22]$. All measurements were in centimetres $(\mathrm{cm})$.

\section{Statistical analysis}

The data acquired was analysed using the IBM SPSS version 23.0 from which, mean, standard deviation and T-test based on age and sex were calculated. Using a 95\% confident level, p-value of $<0.05$ was significant. Figure 1 shows a measured carotid artery.

\section{RESULTS}

Out of the total 104 subjects, the males were 62 and females 42 . The average age of the subjects was $28.32 \pm 9.09$ years. The average height, weight, body mass index and blood pressure of the subjects were $1.72 \pm 0.06 \mathrm{~m}, 67.65 \pm 12.42 \mathrm{~kg}, 22.84 \pm 4.15 \mathrm{~kg} / \mathrm{m}^{2}$ and $113.92 \pm 13.46 / 73.40 \pm 9.84 \mathrm{mmHg}$, respectively. As shown in the Table 1, the results of this study showed that there are differences in measurements between the two sexes (males slightly higher than females in CCA and females higher than males in ICA and ECA) and between right and left sides (with right side slightly higher); however, they are not statistically significant. The right diameter measurements for CCA are, males = $0.63 \pm 0.09$, females $=0.61 \pm 0.07$; for ICA, males $=$ $0.60 \pm 0.09$, females $=0.61 \pm 0.10$; for $\mathrm{ECA}$, males $=$ $0.49 \pm 0.08$, females $=0.51 \pm 0.09$. The left diameter measurements for CCA, males $=0.60 \pm 0.09$, females $=$ $0.59 \pm 0.06$; for ICA, males $=0.60 \pm 0.07$, females $=$ $0.61 \pm 0.07$; for $\mathrm{ECA}$, males $=0.47 \pm 0.14$, females $=$ $0.49 \pm 0.07$. From this study, the average luminal diameter for both sexes for the CCA $=0.61 \pm 0.08 \mathrm{~cm}, I C A=$ $0.60 \pm 0.08 \mathrm{~cm}$ and $\mathrm{ECA}=0.49 \pm 0.10 \mathrm{~cm}$. Reference range of values for the diameters of the carotid arteries within which diameters can be said to be normal were 


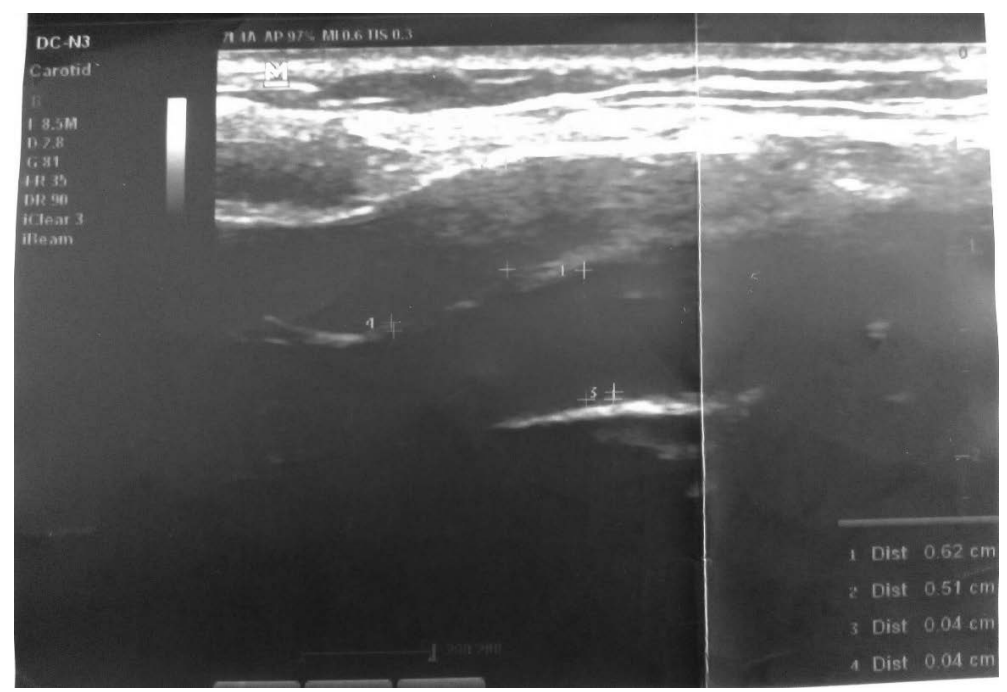

Figure 1. Doppler scan of carotid arteries with measurements.

Table 1. Descriptive statistics of the measured dimensions of the carotid arteries

\begin{tabular}{|c|c|c|c|c|c|c|}
\hline \multirow[t]{2}{*}{ Carotid artery diameter [cm] } & \multicolumn{3}{|c|}{ Male $(n=62)$} & \multicolumn{3}{|c|}{ Female $(n=42)$} \\
\hline & Min & Max & Mean \pm SD & Min & Max & Mean \pm SD \\
\hline \multicolumn{7}{|l|}{ Right } \\
\hline CCA diameter & 0.46 & 0.83 & $0.63 \pm 0.09$ & 0.43 & 0.77 & $0.61 \pm 0.07$ \\
\hline ICA diameter & 0.35 & 0.81 & $0.60 \pm 0.09$ & 0.27 & 0.79 & $0.61 \pm 0.10$ \\
\hline ECA diameter & 0.31 & 0.71 & $0.49 \pm 0.08$ & 0.33 & 0.79 & $0.51 \pm 0.09$ \\
\hline \multicolumn{7}{|l|}{ Left } \\
\hline CCA diameter & 0.42 & 0.77 & $0.60 \pm 0.09$ & 0.47 & 0.70 & $0.59 \pm 0.06$ \\
\hline ICA diameter & 0.39 & 0.73 & $0.60 \pm 0.07$ & 0.43 & 0.81 & $0.61 \pm 0.07$ \\
\hline ECA diameter & -0.43 & 0.71 & $0.47 \pm 0.14$ & 0.26 & 0.66 & $0.49 \pm 0.07$ \\
\hline
\end{tabular}

Min — minimum; Max — maximum; SD — standard deviation; CCA — common carotid artery; ICA — internal carotid artery; ECA — external carotid artery

Table 2. Reference value ranges for the diameters of the carotid arteries

\begin{tabular}{lccc}
\hline Parameter $(\mathbf{c m})$ & Male & Female & Total \\
\hline Common carotid artery diameter & $0.46-0.74$ & $0.44-0.79$ & $0.45-0.76$ \\
Internal carotid artery diameter & $0.45-0.76$ & $0.44-0.75$ & $0.44-0.75$ \\
External carotid artery diameter & $0.34-0.65$ & $0.26-0.69$ & $0.30-0.67$ \\
\hline
\end{tabular}

calculated using the formulae according to Kirkwood and Sterne (2003) [6]; Lawless and Fredette (2005) [11] below and are represented in Table 2 .

$$
\begin{aligned}
& \text { LOWER LIMIT }=m-t_{0.975, \infty} \times \sqrt{\frac{n+1}{n}} \times S . D \\
& \text { UPPER LIMIT }=m+t_{0.975, \infty} \times \sqrt{\frac{n+1}{n}} \times S . D
\end{aligned}
$$

where, $t_{0.975, \infty}=1.96, \mathrm{n}$ - sample size, S.D - standard deviation $[6,11]$.

\section{DISCUSSION}

Carotid artery lumen plays an important role in clinical practice in the cardiovascular as well as vascular neurosurgical sectors. The importance of normal reference values to guide diagnostic and operative work up in-patient care cannot be overemphasized. The lack of Nigerian data with normal anatomical range of values for carotid artery diameters is one major problem this research has solved. Relying solely on foreign data is not desirable as there are known and established racial or demographic differences $[7,9,16]$ that would also affect clinical decision-making in patient care in Nigeria. More so, the carotid arteries are not all the same in calibre and morphology $[2,21]$. Furthermore, from our study, the proximity in diameter of the lumen of the internal carotid artery $(0.60 \mathrm{~cm})$ to that of the common carotid artery $(0.61 \mathrm{~cm})$ confirms that the former is a direct branch of the later as noted in embryology of the vessels as 
they both developed from the same third aortic arch. Whereas, a wide difference is noted between the CCA and the ECA $(0.49 \mathrm{~cm})$, which developed from a different source (ventral pharyngeal artery) [3].

Review of similar studies in Sweden, by Jensen-Urstad et al. [5] noted the mean CCA in Swedish males and females as $0.63 \pm 0.6 \mathrm{~cm}$ and $0.56 \pm 0.5 \mathrm{~cm}$, respectively with significant difference between the two sexes. However, in our index Nigerian study mean CCA diameter for males and females were $0.62 \pm$ $\pm 0.09 \mathrm{~cm}$ and $0.60 \pm 0.07 \mathrm{~cm}$, respectively, where we find close values with that of the Swedish study only in the males but noted higher values in our females in comparison to that of the Swedish. In the United States, one study by Krejza et al. [9] gave normal values of diameter of CCA of males and females as $0.65 \pm 0.98 \mathrm{~cm}$ and $0.61 \pm 0.80 \mathrm{~cm}$, respectively. In another study by Hwaung et al. [4], mean total values for the females $(0.62 \pm 0.88 \mathrm{~cm})$ were higher than those for the males $(0.57 \pm 0.79 \mathrm{~cm})$ in same country. This is similar to our study with the diameters of ICA and ECA, where the values for females were higher than those of males. Although there was significant difference between the sexes with reference to the diameters of the carotid in the study by Hwaung et al. [4], we did not record the same significance.

Whereas our values for CCA in the males were lower than those from Sweden and those from one study in the United States, we had higher values for CCA in our females in comparison to those from Sweden $[5,9]$. We also had higher values in our males compared with those of the second study from United States with relatively lower values in our females to theirs [4]. Our values were higher on both sides for the values published from an Iraqi study [17], where diameter of right CCA $=0.60 \pm 0.7 \mathrm{~cm}$ and left $\mathrm{CCA}=0.58 \pm 0.7 \mathrm{~cm}$.

In a Nigerian study, Agunloye and Owolabi [1] worked on two cohort groups of patients. The 'controls' were hypertensive patients without any form of cerebrovascular accident and the 'cases' were hypertensive patients with any form of cerebrovascular accident. The results of the CCA diameters obtained for the 'controls' (right CCA $=0.59 \pm 0.07 \mathrm{~cm}$ and left CCA $=0.58 \pm 0.12 \mathrm{~cm}$ ) [1] were similar to those of our index study but slightly lower $(0.62 \pm 0.08 \mathrm{~cm}$ and $0.59 \pm 0.08 \mathrm{~cm}$, respectively). One would have expected their values to be higher than normal healthy subjects as in our study based on the hypertensive factor $[15,20]$; however, this was not the case. It may be that the degree of hypertension in the 'control' group at that time had not affected the diameter of the subjects just as there were no clinical signs or symptoms of stroke. This is an important point to note as the values of carotid artery diameter from the 'case' group, which were those hypertensives patients with any form of cerebrovascular event (right $\mathrm{CCA}=0.66 \pm 0.10 \mathrm{~cm}$ and left $\mathrm{CCA}=0.63 \pm 0.10$ $\mathrm{cm}$ ) were much higher than values from our study.

Since we were dealing with apparently healthy population with the aim of providing reference values, it was important to restrict the extremes of age. We believe the age bracket and body size of the subjects could have also played key roles in determining the diameter of the carotid arteries in our index study as they were mostly young adults with normal body size and blood pressure with no obvious clinical comorbidities, where age and weight related changes have not become evident. This select population was important for the inclusion criteria as laboratory serum investigations which were termed invasive were not also intended.

\section{Limitations of the study}

The study did not include laboratory work up of the subjects, such as serum cholesterol, as the were no intents or consent for invasive investigations of the subjects.

\section{CONCLUSIONS}

This sonographic study on healthy Nigerian adults has given us normal reference values for the luminal diameters of the carotid arteries (CCA, ICA and ECA), which clinicians can refer to, when assessing carotid artery diameters of patients in Nigeria for clinical decision making. It also establishes that, although there are notable differences in values from different populations across countries, the Nigerian population has peculiar carotid artery diameter values, having higher values than some countries and lower for others, which needed to be established as the largest black nation in the world. It is also possible to infer the embryological relation between the CCA and the ICA based on their proximity in luminal size from our study.

Conflict of interest: None declared 


\section{REFERENCES}

1. Agunloye AM, Owolabi MO. Exploring carotid sonographic parameters associated with stroke risk among hypertensive stroke patients compared to hypertensive controls. J Ultrasound Med. 2014; 33(6): 975-983, doi: 10.7863/ ultra.33.6.975, indexed in Pubmed: 24866604.

2. Al-Rafiah A, EL-Haggagy AA, Aal IHA, et al. Anatomical study of the carotid bifurcation and origin variations of the ascending pharyngeal and superior thyroid arteries. Folia Morphol. 2011; 70(1): 47-55, indexed in Pubmed: 21604253.

3. Dungan DH, Heiserman JE. The carotid artery: embryology, normal anatomy, and physiology. Neuroimaging Clin N Am. 1996; 6(4): 789-799, indexed in Pubmed: 8824131.

4. Hwaung $\mathrm{P}, \mathrm{Heo} \mathrm{M}$, Bourgeois B, et al. Greater height is associated with a larger carotid lumen diameter. Medicines. 2019; 6(2): 57, doi: 10.3390/medicines6020057.

5. Jensen-Urstad K, Jensen-Urstad M, Johansson J. Carotid artery diameter correlates with risk factors for cardiovascular disease in a population of 55-year-old subjects. Stroke. 1999; 30(8): 1572-1576, doi: 10.1161/01.str.30.8.1572.

6. Kirkwood B, Sterne J. Essential Medical Statistics. 2nd Ed. lackwell Publishing Ltd 2003: 56-57.

7. Koskinen SM, Soinne L, Valanne L, Silvennoinen $H$. The normal internal carotid artery: a CTA study. In: European Society of Radiology. 2014 [Internet]. www.myESR.org.

8. Kpuduwei SPK. Clinical Basis for the Knowledge of Anatomy of Carotid Artery: A Review Article. Yenagoa Med J. 2020; 2(3): 23-28.

9. Krejza J, Arkuszewski M, Kasner SE, et al. Carotid artery diameter in men and women and the relation to body and neck size. Stroke. 2006; 37(4): 1103-1105, doi: 10.1161/01.STR.0000206440.48756.f7, indexed in Pubmed: 16497983.

10. Labropoulos N, Zarge J, Mansour MA, et al. Compensatory arterial enlargement is a common pathobiologic response in early atherosclerosis. Am J Surg. 1998; 176(2): 140-143, doi: 10.1016/s0002-9610(98)00135-4, indexed in Pubmed: 9737619.

11. Lawless JF, Fredette $M$. Frequentist prediction intervals and predictive distributions. Biometrika. 2005; 92(3): 529-542, doi: 10.1093/biomet/92.3.529.

12. Manterola $H L$, Lo Vercio L, Díaz $A$, et al. Validation of an open-source tool for measuring carotid lumen diameter and intima-media thickness. Ultrasound Med Biol. 2018; 44(8): 1873-1881, doi: 10.1016/j.ultrasmedbio.2018.04.001, indexed in Pubmed: 29773245.

13. Meng L, Hou W, Chui J, et al. Cardiac output and cerebral blood flow: the integrated regulation of brain perfusion in adult humans. Anesthesiology. 2015; 123(5): 1198-1208, doi: 10.1097/ALN.0000000000000872, indexed in Pubmed: 26402848.

14. Onaizah O, Poepping TL, Zamir M. A model of blood supply to the brain via the carotid arteries: Effects of obstructive vs. sclerotic changes. Med Eng Phys. 2017; 49: 121-130, doi: 10.1016/j.medengphy.2017.08.009, indexed in Pubmed: 28917828.

15. Päivänsalo M, Merikanto J, Jerkkola T, et al. Effect of hypertension and risk factors on diameters of abdominal aorta and common iliac and femoral arteries in middle-aged hypertensive and control subjects. Atherosclerosis. 2000; 153(1): 99-106, doi: 10.1016/s0021-9150(00)00374-9.

16. Ranadive $S M$, Yan $H$, Lane $A D$, et al. Aerobic exercise training and arterial changes in african americans versus caucasians. Med Sci Sports Exerc. 2016; 48(1): 90-97, doi: 10.1249/MSS.0000000000000742, indexed in Pubmed: 26225767.

17. Rashid SA, Mahmud SA. Correlation between carotid artery intima-media thickness and luminal diameter with body mass index and other cardiovascular risk factors in adults. Sultan Qaboos Univ Med J. 2015; 15(3): e344-e350, doi: 10.18295/squmj.2015.15.03.007, indexed in Pubmed: 26357554.

18. Roman MJ, Naqvi TZ, Gardin JM, et al. Emile mohler. American association echocardiographers- clinical-app-of-noninvasive-vasc-us-in-cv-risk-stratification.pdf. J Am Soc Echocardiogr. 2006; 19: 943-954.

19. Saba L, Banchhor SK, Araki T, et al. Intra- and inter-operator reproducibility of automated cloud-based carotid lumen diameter ultrasound measurement. Indian Heart J. 2018; 70(5): 649-664, doi: 10.1016/j.ihj.2018.01.024, indexed in Pubmed: 30392503.

20. Sedaghat S, van Sloten TT, Laurent S, et al. Common carotid artery diameter and risk of cardiovascular events and mortality: pooled analyses of four cohort studies. Hypertension. 2018; 72(1): 85-92, doi: 10.1161/HYPERTENSIONAHA. 118.11253, indexed in Pubmed: 29785959.

21. Sheikh-Bahaei N, Matys T, Gillard JH. Anatomy of the neck arteries. In: Neurovascular Imaging: From Basics to Advanced Concets. Sringer, New York 2016: 87-94.

22. Terminology and Diagnostic Criteria Committee, Japan Society of Ultrasonics in Medicine. Standard method for ultrasound evaluation of carotid artery lesions. J Med Ultrasonics. 2009; 36(4): 219-226, doi: 10.1007/s10396009-0238-y.

23. Tolezani EC, Costa-Hong V, Correia G, et al. Determinants of functional and structural properties of large arteries in healthy individuals. Arq Bras Cardiol. 2014; 103(5): 426-432, doi: 10.5935/abc.20140124, indexed in Pubmed: 25211201.

24. Wikstrand J. Methodological considerations of ultrasound measurement of carotid artery intima-media thickness and lumen diameter. Clin Physiol Funct Imaging. 2007; 27(6): 341-345, doi: 10.1111/j.1475-097X.2007.00757.x, indexed in Pubmed: 17944655.

25. Woldeyes DH. Anatomical variations of the common carotid artery bifurcations in relation to the cervical vertebrae in ethiopia. Anat Physiol Curr Res. 2014; 4(3): 1-3. 